\title{
Improving hand sensibility in vibration induced neuropathy: A case-series
}

\author{
Birgitta Rosén*, Anders Björkman and Göran Lundborg
}

\begin{abstract}
Objectives: We report a long-term series of nine workers suffering from vibration-induced neuropathy, after many years of exposure to hand-held vibrating tools at high or low frequency. They were treated with temporary selective cutaneous anaesthesia (EMLA ${ }^{\circledR}$ cream) of the forearm repeatedly for a period up to one year (in two cases four years). The aim was to improve their capacity to perceive touch and thereby improve hand function and diminish disability. The treatment principle is based on current concepts of brain plasticity, where a deafferentation of a skin area results in improved sensory function in adjacent skin areas.
\end{abstract}

Methods: All participants had sensory hand problems in terms of numbness (median touch thresholds $>70$ mg) and impaired hand function influencing ADL (mean DASH score 22).

After an initial identical self-administered treatment period of 8 weeks (12-15 treatments with increasing intervals) they did one treatment every 2-3 month.

Results: After one year sensibility (touch thresholds and tactile discrimination) as well as hand function (mean DASH score 13) were improved in a majority of the cases. Seven of the participants choose to continue the treatment after the first year and two of them have continued at a regular basis for up to four years. A surprising, secondary finding was diminishing nocturnal numbness of the hand and arm in eight of the nine subjects from "frequently" to "hardly ever or never".

Conclusions: Our observations open new perspectives for treatment of impaired sensibility and hand function in a group of patients with vibration induced hand problems where we have no treatment to offer today.

\section{Introduction}

The use of handheld vibrating tools is common in many occupations where low- as well as high frequency vibrating tools is used. However, long-term use of vibrating tools constitutes an occupational health risk, and various neurological and vasospastic symptoms are common, for example sensory disturbances, pain, intolerance to cold, reduced grip strength, and reduced tactile dexterity with fumbling [1-4]. Hand function may be severely impaired over the years and may affect the ability to work and quality of life [5-7]. In the long term perspective vibration exposure can lead to hand-arm-vibration syndrome, a complex condition with sensory and musculoskeletal as well as vascular symptoms [4]. Vibration-induced neuropathy is sometimes combined with carpal tunnel syndrome, and it is often difficult to differentiate

\footnotetext{
* Correspondence: birgitta.rosen@med.lu.se

Department of Hand Surgery, Skåne University Hospital Malmö, Sweden
}

between them $[8,9]$. Apart from ergonomic measures there is, at present, no effective treatment for the neuropathy.

Peripheral nerve injury and neuropathy result in changes in the central nervous system $[10,11]$, and we have demonstrated, using magnetic resonance technique (fMRI), that also patients exposed to handheld vibrating tools and with sensory disturbances in their hands also show cortical changes with significantly larger activated cortical volumes and fusion of digital representations in the primary somatosensory cortex (S1) $[12,13]$. The findings are similar to those in conditions such as hand dystonia [14,15] with loss of motor control in individual fingers following long time repetitive synchronous movements of the digits [15]. Such functional impairments are probably the result of cortical reorganisation following long-term non-physiological sensory input [16] and they may also partly explain the symptoms seen in patients with vibration-induced neuropathy.

\section{() Biomed Central}


All parts of the body are represented in a sensory cortical body map [17] which is constantly modulated in response to the afferent nerve impulses [18-20]. Increased tactile experience or acute deafferentation of a body part results in rapid cortical reorganisation [20,21].

Treatment with temporary selective cutaneous anaesthesia using an anaesthetic cream (EMLA $\left.{ }^{\circledR}\right)$ containing 2.5\% lidocain and 2.5\% priolocain, AstraZeneca, Södertälje, Sweden) on the forearm to improve the sensory function of the hand, is a new method based on rapid cortical plasticity [22]. The EMLA ${ }^{\circledR}$ treatment concept is an example of guided plasticity [23] where the ability of the CNS to change is used for therapeutic purposes. Cutaneous anaesthesia of the forearm results in expansion of the cortical hand area in the $\mathrm{S} 1$ and thus more nerve cells being made available to the hand. In healthy subjects we have used fMRI technique to demonstrate that cutaneous anaesthesia of the forearm skin induces a cortical reorganisation, resulting in expansion of the cortical hand representation. In conjunction with the cortical expansion the sensory function of the hand improved significantly [24].

Application of EMLA ${ }^{\circledR}$ ) to the forearm is a simple and non-invasive method that results in a deafferentation of the forearm in the somatosensory cortex which allows the hand to expand on the forearm area in the $S 1$, resulting in more nerve cells supplying the hand [24]. Clinically the sensory function of the hand improves following EMLA ${ }^{\circledR}$ ) application to the forearm $[22,24,25]$. The method works in the upper as well as lower extremity in healthy individuals and also enhances the effect of sensory re-education in patients following peripheral nerve repair [22,25,26]. Earlier we described application of the method in a single-case of vibration-induced neuropathy [27]. However, the long-term effect is of interest, and here we present a series of nine pilot cases in which the method has been used for up to four years.

\section{Methods}

\section{Selection of Cases}

During 2006-2009 a total of fifteen consecutive patients with a history of neuropathy induced by long term exposure to vibrating handheld tools were referred to the Department of Hand Surgery in Malmö with the specific question: "is EMLA ${ }^{\circledR}$ treatment a possible way of improving the impaired hand function?" (Table 1).

They patients had impaired touch thresholds in the fingers as measured with Semmes-Weinstein monofilaments (> monofilament \# $2.83=70 \mathrm{mg}$ ), and subjective sensory disturbances with e.g. dyscoordination and impaired dexterity.

EMLA $^{\circledR}$ treatment specifically addresses sensory disturbances, and five of the referred cases were excluded at an early stage and subjected to further examination or other treatment, because their problems were not primarily sensory.

After the initial treatment period of eight weeks, nine of the patients showed improved touch thresholds and tactile discrimination, they also subjectively experienced improvement and wanted to continue the treatment. In one patient sensory function did not improve at all subjectively or objectively - and there was no wish to continue the treatment.

In the group of nine patients who wanted to continue EMLA $^{\circledR}$ treatment, four had been exposed to high-frequency vibrating tools (dental hygienists, dental technicians), and five had been exposed to low-frequency vibrating tools (car or lorry mechanics, road construction worker). Two of the participants had retired and seven were in full-time employment, one worked part-

Table 1 Demographic and clinical characteristics at baseline

\begin{tabular}{|c|c|c|c|c|c|c|c|c|}
\hline $\begin{array}{l}\text { Subj } \\
\text { nr }\end{array}$ & Gender & Age & $\begin{array}{l}\text { Years of } \\
\text { exposure }\end{array}$ & $\begin{array}{l}\text { Nocturnal } \\
\text { numbness }\end{array}$ & $\begin{array}{l}\text { Touch threshold at } \\
\text { fingertip level* (g, median) }\end{array}$ & $\begin{array}{l}\text { Tactile discrimination } \\
\text { at fingertip level } \\
(2 \mathrm{PD}, \text { median })^{* *}\end{array}$ & $\begin{array}{l}\text { Dexterity (Purdue } \\
\text { pegboard) } * * *\end{array}$ & $\begin{array}{l}\text { Disability (DASH- } \\
\text { score) } * * * *\end{array}$ \\
\hline 1 & Female & 65 & 19 & frequent & 0.07 & 4 & 16 & 9 \\
\hline 2 & Female & 65 & 25 & sometimes & 0.4 & $\geq 16$ & 5 & 33 \\
\hline 3 & Female & 48 & 29 & sometimes & 0.16 & 3.7 & 16 & 7.5 \\
\hline 4 & Female & 47 & 20 & frequent & 0.16 & 3.4 & 13 & 39 \\
\hline 5 & Male & 64 & 45 & frequent & 0.4 & 4 & 8 & 37 \\
\hline 6 & Male & 57 & 40 & $\begin{array}{l}\text { hardly ever/ } \\
\text { never }\end{array}$ & 0.16 & 4.3 & 13 & 26 \\
\hline 7 & Male & 30 & 13 & frequent & 0.16 & 3.4 & 18 & 14 \\
\hline 8 & Male & 37 & 15 & sometimes & 0.04 & 3.4 & 14 & 14 \\
\hline 9 & Male & 60 & 40 & sometimes & 1.0 & 10 & 10 & 11 \\
\hline
\end{tabular}

* Semmes-Weinstein monofilaments (20 probes $0.008 \mathrm{~g}-300 \mathrm{~g}$ ), normal $\leq 0.07 \mathrm{~g}$

** Two-point discrimination, normal $\leq 5 \mathrm{~mm}$

*** Number of pegs picked up and placed during 30 seconds

**** Disability of the arm, shoulder and hand, normal $\leq 10$ 
time for six months in the middle of the treatment period (subject no 7). Demographics at referral are shown in Table 1.

The study was conducted according to the Helsinki Declaration, the local ethics committee approved the study design, and all participants gave their consent.

\section{EMLA $^{\circledR}$ treatment and follow-up}

We used a recently presented protocol for treating hand conditions with diminished sensory function (minimum protective sensibility) using a treatment programme in which the skin of the forearm is repeatedly anaesthetised by cutaneous application of EMLA ${ }^{\circledR}$ cream [25]. Prior to the treatment a medical history was taken focusing on adverse effects from prior use of local anaesthetic agents, including allergic reactions. Vibration-induced neuropathy is frequently bilateral and EMLA ${ }^{\circledR}$ was applied to the arm subjectively considered to be the most symptomatic. The cream was applied under an occlusive bandage, for 90 minutes to the flexor aspect of the forearm, over an area stretching from the wrist and $15 \mathrm{~cm}$ proximally. After 90 minutes, the EMLA ${ }^{\circledR}$ was carefully washed off.

This initial treatment showed improvement in sensory functions with improved touch thresholds and/or improved tactile gnosis (Table 2). The nine persons were then offered an 8-week treatment period (12-15 EMLA ${ }^{\circledR}$ applications in descending frequency) based on self-administered treatments and regular follow-ups. This entailed three treatments in the first week, two treatments in weeks 2-6, and one treatment in weeks 7-8. Subsequently, "booster doses" were given once every month over one year if the patient experienced improvement.
The participants were also instructed to perform a simple sensory re-education program [28] several times a day during the initial eight-week treatment period.

Assessment of hand function was performed according to standardised methods (ASHT, 1992), at regular intervals for up to one year after initiating the treatment.

A full set of 20 Semmes-Weinstein Monofilaments (SWM) was used for assessment of touch thresholds at fingertip level, two-point discrimination (2PD) at the tips of digits II and V for assessment of tactile discrimination (carried out according to the "Moberg method" [29]) in a descending order, starting with $15 \mathrm{~mm}$ to assess the level at which responses were correct. Dexterity was assessed using Purdue Pegboard [29], and grip strength using Jamar dynamometer [29]. For assessment of disability the DASH (disability of the arm hand and shoulder) questionnaire was used [30]Assessments were performed prior to and after initial treatment, after 8 weeks, 6 months and 1 year.

\section{Analysis}

The majority of the data was ordinal and a nonparametric statistical method - Wilcoxon signed rank test was used to calculate the changes in status before treatment and after one year. Due to the small sample size only two time points - before treatment and after one year - were calculated.

\section{Result}

The results for the nine subjects after treatment for one year are summarised in Table 2. Touch thresholds improved significantly $(\mathrm{p}=0.01)$, as did level of

Table 2 Result after treatment over 1 year with EMLA ${ }^{\circledR}$ cream in nine persons with subjective problems after longterm exposure to hand-held vibrating tools

\begin{tabular}{|c|c|c|c|c|}
\hline & $\begin{array}{l}\text { Pre } \\
\text { treatment }\end{array}$ & $\begin{array}{l}\text { After } 1 \\
\text { treatment }\end{array}$ & $\begin{array}{l}\text { After } 8 \text { weeks ( } 15 \\
\text { treatments) }\end{array}$ & $\begin{array}{l}\text { After } 1 \text { year (one treatment } \\
\text { every } 2-3 \text { months) }\end{array}$ \\
\hline $\begin{array}{l}\text { Touch thresholds (Semmes Weinstein monofilaments, g) } \\
\text { Normal } \leq 0.07 \mathrm{~g} \text { median }\end{array}$ & $\begin{array}{l}0.16(0.04- \\
1.0)\end{array}$ & $\begin{array}{c}0.04(0.04- \\
0.5)\end{array}$ & $0.04(0.04-0.2)$ & $0.04(0.02-0.07)$ \\
\hline $\begin{array}{l}\text { Tactile discrimination ( } 2 \text { point discrimination, } \mathrm{mm} \text { ), } \\
\text { normal } \leq 5 \mathrm{~mm} \text { mean }\end{array}$ & $\begin{array}{l}5.8(3.4- \\
\quad \geq 16)\end{array}$ & $3.3(2.2-5.0)$ & $3.8(2.8-8.0)$ & $3.1(2.2-5.0)$ \\
\hline $\begin{array}{l}\text { Dexterity (Purdue Peg Board, number of pegs picked and } \\
\text { placed), mean }\end{array}$ & $13(5-18)$ & $\begin{array}{l}\text { Not } \\
\text { evaluated }\end{array}$ & $13(9-18)$ & 15 (10-17) \\
\hline Disability (DASH-score, normal below 10), mean & $22(8-39)$ & $\begin{array}{l}\text { Not } \\
\text { evaluated }\end{array}$ & Not evaluated & $13(0-32)$ \\
\hline Grip strength (Jamar, second position, kg), mean & $37(16-62)$ & $\begin{array}{l}\text { Not } \\
\text { evaluated }\end{array}$ & $38(22-62)$ & $41(28-67)$ \\
\hline
\end{tabular}

Nocturnal numbness (Number of subjects)

\begin{tabular}{lccc} 
Frequently: & 4 & Not & 0 \\
& & evaluated & 2 \\
Sometimes & 4 & 1 & 7 \\
Hardly ever/never & 1 & 8 \\
\hline
\end{tabular}

Median or mean are registered, and range given within brackets. 
disability expressed in a lowered DASH-score $(\mathrm{p}=0.03)$. A 10-point decrease in the DASH score is considered a clinically meaningful change [31], and the mean change in the present study was 9 .

Dexterity improved in five of the participants, however not significantly on group level. No changes were seen in grip strength.

After one year eight of the nine subjects decided to continue the treatment with applications of EMLA ${ }^{\circledR}$ every 2-3 months.

Subject \# 1 has previously been described in a case report and like subject \#5, has now undergone the treatment with EMLA ${ }^{\circledR}$ on a regular self-administered basis for four years. They, as well a majority of the group, said that they can "feel" when a treatment is needed, depending on level of manual activity and season. Sensory status is normally better during warmer periods.

\section{Discussion}

This case series shows that repeated cutaneous application of an anaesthetic cream, EMLA ${ }^{\circledR}$, to the volar aspect of the forearm for 90 minutes in 15 treatments during an eight-week period, results in subjectively, as well as objectively, improved hand function and reduced disability in persons with vibration-induced neuropathy. With booster doses the result lasted at least one year. After one year eight of the nine subjects to date decided to continue the treatment with applications of EMLA ${ }^{\circledR}$ every 2-3 months, and two participants have continued treatment for up to four years, maintaining the result.

Extensive simultaneous sensory or motor stimulation of the digits can produce a use-dependent cortical reorganisation of digital receptive fields. There are several situations where an unfysiological sensory input eventually induces a reorganisation of the cortical hand map in analogy with that which can be found after long term work with hand-held vibrating tools $[14,32,33]$. In such situations the cortical hand map is distorted and rearranged into a disorganized pattern.

In humans, normal stimulation on the fingers generated by everyday use of the hands is non-simultaneous. Studies on primates [16,34] and humans [35] have shown that synchronous stimulation of multiple digits results in a breakdown of the normally sharply segregated representations of adjacent digits in the primary somatosensory cortex to multiple-digit receptive fields covering two or three adjacent digits.

We have previously shown, using fMRI at 3T, that the activated volumes in the hand area of the primary somatosensory cortex were significantly larger in persons with neuropathy due to long-term exposure to high-frequency vibrations than in healthy controls. The normal finger somatotopy was changed to a pattern where the individual fingers overlap each other. Furthermore, activation in the primary motorcortex was weaker and more scattered in the neuropathy group compared to controls [13].

Cutaneous local application of an anaesthetic cream, where the deafferented area can be precisely controlled, is a simple treatment. Following an initial application session at the hospital, self-administration is possible at home for a well-informed patient. Care has to be taken as the protective sensation on the forearm is impaired for a few hours after the application of the cream. The anaesthetic agent EMLA ${ }^{\circledR}$ has been widely tested, and has no, or few, known side effects [36]. In the present group one of the subjects had a rash on the skin for a few hours after one of the applications. In routine practice, temporary anaesthesia using EMLA ${ }^{\circledR}$ is followed by rapid and complete normalisation of all sensory functions in the body-part treated [36].

The clinical effect of the deafferentation is already obvious 90 minutes after application indicating that unmasking of pre-existing synaptic connections is the mechanism underlying the rapid modulation of sensory function [37].

A surprising, but interesting, finding was that the treatment acted positively on carpal tunnel-like symptoms such as nocturnal numbness (Table 2), which is a common problem in vibration-induced neuropathy [8]. Although difficult to explain this is probably also an effect of the cortical reorganisation induced by the cutaneous anaesthesia.

The well-developed feedback system between the hand and the brain, with continuous proprioception and tactile input that are coordinated with memory systems in the brain, is a prerequisite for regulation of grip force and grip speed [38] Restoration of this feedback system is one of the aims after EMLA ${ }^{\circledR}$ treatment and possibly explains the improved functional use of the hand. The training of discriminative sensibility that is a part of the treatment - sensory re-education exercises - is possibly an important factor in such restoration of the fine-tuned receptive fields in the somatosensory cortex.

Our findings indicate that repeated cutaneous forearm anaesthesia over an eight-week period can improve hand function, focusing on sensation. With booster doses of EMLA $^{\circledR}$ once a month after the initial 8-week treatment we saw a long-lasting effect of up to 4 years in this group.

In a previous study on patients with median and ulnar nerve injuries EMLA ${ }^{\circledR}$ treatment twice a week for two consecutive weeks resulted in a significant clinical improvement lasting at least four weeks after the EMLA $^{\circledR}$ application [25]. The mechanism behind this is probably a rapid unmasking of existing neural substrates but through a repeated deafferentation may create a 
more long lasting "time window" that will enable the patient to better consolidate the cortical changes thus producing a longer lasting improvement.

We would like to emphasise that the method described here, for improving sensory function in workers exposed to vibrating tools, in no way replaces ergonomic measures to minimize such exposure but may rather be seen as an additional measure.

Our observations open up interesting new perspectives regarding future possibilities for improving hand function and reducing disability in a group of patients, for whom no treatment is available today, using a simple and non-invasive method.

Our observations are encouraging, indicating a new principle for treatment of vibration-induced neuropathy of the hand, and perhaps also for other neuropathies. However, this is an initial series of cases in a long-term study, and the optimal protocol concerning time, dose, and practical handling of the cream aimed at achieving a long-lasting or permanent effect on sensory recovery has yet to be defined in larger randomized controlled studies.

\section{Acknowledgements}

This work was supported by grants from the Swedish Council for Working Life and Social Research; the Swedish Medical Research Council; Faculty of Medicine, Lund University; Malmö University Hospital.

\section{Authors' contributions}

BR carried out the EMLA ${ }^{\oplus}$ ) treatment. BR, $A B$ and GL carried out the design of the study, analysis of data and drafting of this manuscript. All authors have read and approved the final manuscript.

\section{Competing interests}

The authors declare that they have no competing interests.

Received: 25 November 2010 Accepted: 27 April 2011

Published: 27 April 2011

\section{References}

1. House R, Wills M, Liss G, Switzer-McIntyre S, Manno M, Lander L: Upper extremity disability in workers with hand-arm vibration syndrome. Occup Med (Lond) 2009, 59:167-173.

2. Hagberg M, Burstrom L, Lundstrom R, Nilsson T: Incidence of Raynaud's phenomenon in relation to hand-arm vibration exposure among male workers at an engineering plant a cohort study. J Occup Med Toxicol 2008, 16(3):13.

3. Dahlin LB, Lundborg G: Vibration-induced hand problems: role of the peripheral nerves in the pathophysiology. Scand J Plast Reconstr Surg Hand Surg 2001, 35:225-232.

4. Bovenzi $M$, Griffin MJ, Hagberg M: New understanding of the diagnosis of injuries caused by hand-transmitted vibration. Int Arch Occup Environ Health 2008, 81:505.

5. Cederlund R, Iwarsson S, Lundborg G: Quality of life in Swedish workers exposed to hand-arm vibration. Occup Ther Int 2007, 14:156-169.

6. Cederlund R, Nordenskiold U, Lundborg G: Hand-arm vibration exposure influences performance of daily activities. Disabil Rehabil 2001, 23:570-577.

7. Poole K, Mason H: Disability in the upper extremity and quality of life in hand-arm vibration syndrome. Disabil Rehabil 2005, 27:1373-1380.

8. Palmer KT, Harris EC, Coggon D: Carpal tunnel syndrome and its relation to occupation: a systematic literature review. Occup Med (Lond) 2007, 57:57-66.
9. van Rijn RM, Huisstede BM, Koes BW, Burdorf A: Associations between work-related factors and the carpal tunnel syndrome-a systematic review. Scand J Work Environ Health 2009, 35:19-36.

10. Merzenich MM, Jenkins WM: Reorganization of cortical representations of the hand following alterations of skin inputs induced by nerve injury, skin island transfers, and experience. Journal of Hand Therapy 1993, 6:89-104.

11. Taylor KS, Anastakis DJ, Davis KD: Cutting your nerve changes your brain. Brain 2009, 132:3122-3133.

12. Lundborg G, Rosen B, Knutsson L, Holtas S, Stahlberg F, Larsson EM: Handarm-vibration syndrome (HAVS): is there a central nervous component? An fMRI study. J Hand Surg (European volume) 2002, 27:514-519.

13. Bjorkman A, Weibull A, Svensson J, Balogh I, Rosen B: Cortical changes in dental technicians exposed to vibrating tools. Neuroreport 2010, 21(10):722-726.

14. Elbert $T$, Rockstroh $B$ : Reorganization of human cerebral cortex: the range of changes following use and injury. Neuroscientist 2004, 10:129-141.

15. Byl NN: Focal hand dystonia may result from aberrant neuroplasticity. Adv Neurol 2004, 94:19-28.

16. Wang $X$, Merzenich MM, Sameshima K, Jenkins WM: Remodelling of hand representation in adult cortex determined by timing of tactile stimulation. Nature 1995, 378:71-75.

17. Penfield W, Boldrey E: Somatic motor and sensory representations in the cerebral cortex of man as studied by electrical stimulation. Brain 1937, 60:389-443.

18. Calford MB: Dynamic representational plasticity in sensory cortex. Neuroscience 2002, 111:709-738

19. Wall JT, Xu J, Wang $X$ : Human brain plasticity: an emerging view of the multiple substrates and mechanisms that cause cortical changes and related sensory dysfunctions after injuries of sensory inputs from the body. Brain Res Brain Res Rev 2002, 39:181-215.

20. Calford MB, Tweedale R: Acute changes in cutaneous receptive fields in primary somatosensory cortex after digit denervation in adult flying fox. J Neurophysiol 1991, 65:178-187.

21. Chen R, Cohen LG, Hallett M: Nervous system reorganization following injury. Neuroscience 2002, 111:761-773.

22. Bjorkman A, Rosen B, Lundborg G: Acute improvement of hand sensibility after selective ipsilateral cutaneous forearm anaesthesia. Eur J Neurosci 2004, 20:2733-2736.

23. Duffau $\mathrm{H}$ : Brain plasticity: from pathophysiological mechanisms to therapeutic applications. J Clin Neurosci 2006, 13:885-897.

24. Bjorkman A, Weibull A, Rosen B, Svensson J, Lundborg G: Rapid cortical reorganisation and improved sensitivity of the hand following cutaneous anaesthesia of the forearm. Eur J Neurosci 2009 29:837-844.

25. Rosen B, Bjorkman A, Lundborg G: Improved sensory relearning after nerve repair induced by selective temporary anaesthesia - a new concept in hand rehabilitation. J Hand Surg [Br] 2006, 31:126-132.

26. Rosen B, Bjorkman A, Weibull A, Svensson J, Lundborg G: Improved sensibility of the foot after temporary cutaneous anesthesia of the lower leg. Neuroreport 2009, 20:37-41.

27. Rosen B, Bjorkman A, Lundborg G: Improved hand function in a dental hygienist with neuropathy induced by vibration and compression: The effect of cutaneous anaesthetic treatment of the forearm. Scand J Plast Reconstr Surg Hand Surg 2008, 42:51-53.

28. Dellon A: Sensibility and re-education of sensation in the hand Williams\&Wilkins Baltimore; 1981.

29. American Society of Hand Therapists (ASHT): Clinical assessment recommendations ASHT; 1992.

30. Beaton DE, Katz JN, Fossel AH, Wright JG, Tarasuk V, Bombardier C: Measuring the whole or the parts? Validity, reliability, and responsiveness of the Disabilities of the Arm, Shoulder and Hand outcome measure in different regions of the upper extremity. $J$ Hand Ther 2001, 14:128-146.

31. Husted JA, Cook RJ, Farewell VT, Gladman DD: Methods for assessing responsiveness: a critical review and recommendations. J Clin Epid 2000, 53:459-468.

32. Elbert T, Candia E, Altemnüller E, Rau H, Sterr A, Rockstroh B, Pantev C, Taub E: Alteration of digital representations in somatosensory cortex in focal hand dystonia. NeuroReport 1998, 9:3571-3575. 
33. Altenmuller E: Focal dystonia: advances in brain imaging and understanding of fine motor control in musicians. Hand Clin 2003, 19:523-538.

34. Clark SA, Allard T, Jenkins WM, Merzenich MM: Receptive fields in the body-surface map in adult cortex defined by temporally correlated inputs. Nature 1988, 332:444-445.

35. Mogilner A, Grossman JA, Ribary U, Joliot M, Volkmann J, Rapaport D, Beasley RW, Llinas RR: Somatosensory cortical plasticity in adult humans revealed by magnetoencephalography. Proc Natl Acad Sci USA 1993 , 90:3593-3597.

36. Juhlin L, Evers H: EMLA: a new topical anesthetic. Adv Dermatol 1990, 5:75-91.

37. Werhahn KJ, Mortensen J, Van Boven RW, Zeuner KE, Cohen LG: Enhanced tactile spatial acuity and cortical processing during acute hand deafferentation. Nat Neurosci 2002, 5:936-938.

38. Johansson RS: Dynamic use of tactile afferent signals in control of dexterous manipulation. Adv Exp Med Biol 2002, 508:397-410.

doi:10.1186/1745-6673-6-13

Cite this article as: Rosén et al:: Improving hand sensibility in vibration induced neuropathy: A case-series. Journal of Occupational Medicine and Toxicology 2011 6:13.

\section{Submit your next manuscript to BioMed Central} and take full advantage of:

- Convenient online submission

- Thorough peer review

- No space constraints or color figure charges

- Immediate publication on acceptance

- Inclusion in PubMed, CAS, Scopus and Google Scholar

- Research which is freely available for redistribution

Submit your manuscript at www.biomedcentral.com/submit 